\title{
Postdigital Positionality as a Learner
}

\section{Learning, Experience and Inclusion as Personal and Embodied, Not Rationally Audited}

We will each have personal ideas on what it means to learn anything. In a broad sense, every person is a learner of some sort, whether they are assessed for formal qualifications or not. However, not all learning comes for free and routes into accessing education can vary greatly depending on each person's situation and context. Despite its potential worth to human beings, an education can be very expensive, and not only in economic terms. Education often involves making sacrifices, some that I can personally identify with, and others that people have shared with me. I have been moved by hearing individual experiences, challenges, discomfort, accounts of 'imposter syndrome', progression, setbacks and successes. People have discussed their living narratives with me as students in classrooms in which I have taught, in tutorials and supervisions, as staff on professional development programmes, in mentoring meetings, over Internetbased communication systems, in different geographical parts of the world (Lamb, Bartholomew \& Hayes, 2017: 214, Traxler, Smith, Scott \& Hayes, 2020) and across time zones and different locations during the 2020 Covid-19 crisis (Peters \& Wang et al., 202O, Jandrić \& Hayes, 202Oa, Jandrić \& Hayes, 202Ob).

Learning through personal experience is different though to simply being told something. I can listen to (and be moved by) these powerful accounts, but I cannot personally embody them. Neither can I label them in any rational terminology that would retain the individuality and authenticity of each person's version of what they learned, how they learned something and the emotions that were involved. Learning through first-hand experiences can effect change in the way that a person perceives the world, and it may alter how they act in it, if they are able to examine their experiences reflexively. The idea of 'lived experience' is also a reminder that this is an active process taking place within a human being's body, even if they are in close interaction with technology too. Their body may, or may not, have a disability, be of a particular gender, ethnicity, or social class, but experiences of feeling included will then be felt across these intersecting factors (Hector, 2020: 66). Thus, it is hard to imagine these intimate authentic accounts from human beings about their experiences of learning, inclusion or discrimination, rendered into something simply called ‘data' or 'the student experience'. 
Yet data can be rich and qualitative, as well as descriptive and summative, or it can be both, depending on how it is collected and with what purposes, in a cultural political economy. The line of argument in this book so far has been that we now occupy a postdigital context where past and present cultural and technological concerns cannot sit apart from each other, or from biological challenges such as Covid-19. Concerns over student wellbeing cannot be isolated in policy from the use of AI to power learning or the IoT to modernise the campus. However, rather than institutions trying to educationalise and regulate all aspects of student experiences within walls that have ceased to exist, there is a role for universities as sites of knowledge at the intersection of key societal debates (Delanty, 2001: 158). Inclusivity is just one of these debates, but it concerns citizenship as a whole, not the student population alone. This shift requires a change of focus away from rational McPolicy towards postdigital positionality.

Universities over recent decades have gathered a lot of data about their own activities as institutions have become increasingly subordinate to what has been described as an 'audit culture'. This has come to embody 'a new rationality of governance' (Shore \& Wright, 1999) where data is collected, and efficiency measured, on many activities surrounding student learning and support (Office for Students, 2019). Not only has this approach involved 'the reinvention of professionals themselves as units of resource whose performance and productivity must constantly be audited so that it can be enhanced' (Shore \& Wright, 1999: 559), this has also reconstructed students as 'vulnerable' beings and even as 'thwarted consumers' (Brooks, 2018: 745). There has been a subtle but ongoing shift where an acknowledgement of the challenges and emotional aspects of learning, such as those I referred to at the start of this chapter, have come to be considered as if these were 'treatable' (Ecclestone \& Hayes, 2019: 155) aspects of the package of 'experience' that students now pay for and universities 'deliver'. A key problem we have faced for some time is that:

The language of markets, targets and tests is not only increasingly regulating education, but is driving out the possibility of other languages and closing the educational field to other possibilities. (Stevenson, 2010: 342 )

This 'consumption of any space for alternative discourse' (Hayes, 2015: 27) has led to new identities being ascribed to students where they routinely require therapeutic interventions to counter the emotionally difficult aspects of learning. Unfortunately, this then leads to a preoccupation with feelings over the challenges of 'mastering a difficult subject' (Ecclestone \& Hayes, 2019: 156) or the assessment that accompanies it. These changes have introduced new 
terminology too, which when placed within rational policy imperatives, takes on an independence from the individual human positionalities I described above. This is because any generalised description of the 'shared trauma' of being a student along with a set of prescribed antidotes is not the same thing as an individual narrative from a person who has overcome challenges to learning. The first is a rationality that treats students as deficient. The second is a positionality from which a student shares details of their personal journey and their identification with eventually becoming proficient.

It is important to stress that these arguments are not against the provision of support for students: far from it. They are though, a critique of a rationale where students are treated as 'lacking' rather than 'operating from a place of plenty' where they might experience and contribute to a 'genuine curiosity and joy in learning' (Kahane, 2009). Kahane argues that: 'students are reminded repeatedly of what they lack and come to treat education as a treadmill to gain praise and avoid humiliation' (Kahane, 2009: 57). Yet even a treadmill requires input from a human to keep it moving and often the hope of improved selfesteem is behind the choice that people make to exercise on a treadmill. Ecclestone and McGiverny (2005: 8) suggest that if educators focus on self-esteem this need not imply 'a view of learners as emotionally frail, weak or vulnerable', instead it implies:

a recognition that, in order to progress, some individuals need to change their self-image and raise their estimation of their talents and potential. (Ecclestone \& McGiverny, 2005: 8)

This however does not seem to be an analysis that sits well with a university culture of writing McPolicy. As previously argued, the linguistic structure of HE McPolicy is distinctive in that it appears to require hardly any input from humans at all (Hayes, 2019a). There is little space for living narratives and literacies because the focus is mostly on describing what detached objects (such as strategies, buzz phrases or technologies) have achieved, rather than accrediting diverse human subjects with the labour of their own learning. McPolicy mostly comments on student experience (not experiences), on digital literacy (not literacies) and therefore what is plural, diverse and ongoing, is simply omitted from these texts. What is static seems to get counted, whilst what is dynamic is frequently discounted. McPolicy does have its advantages though if you wish to discuss humans only in rational terms, as data. Under these circumstances, data may also be assumed to be 'facts', and facts (along with their associated metrics) can form a basis for all kinds of calculations and reasoning that can easily bypass the complications of human positionality. 
Yet McPolicy could have begun to encounter a problem. Whilst this reductive form of discourse may have reinforced the rational governance of some forms of objective quality assurance, accreditation, accountability and so called 'best practices', when it comes to inclusivity policy, it continually falls short. This is because the writing of rational policy for the purposes of diversity and inclusion moves quickly into irrationality, if the activities of people are not mentioned in it. Furthermore, it hits another hurdle when it fails to engage explicitly with new digital developments that now have huge implications for how learning takes place. This includes the potential promise of AI powered education to improve access and approaches to education. It also encompasses the potential technological or commercial bias and ethical concerns surrounding many data-driven systems already actively used for student learning and related analytics. In seeking to measure inclusivity within narrow categories, the diverse fluid encounters of staff and students become reified into static data. This has implications for what then gets excluded. The aspects of identity that are argued to be valued, become absorbed into generalities. This ultimately makes it harder to effect meaningful change in any institution.

Even as I write, a phenomenal amount of data is being processed as the US election vote of 2020 draws to a close amid some dispute over the outcomes by the current president. Earlier in the year, as Covid-19 took hold in many parts of the world, different populations around the globe experienced first-hand the responses of their national leaders and their country's policies towards a pandemic. In the US, it was argued in March 2020: 'America has learned a lot about Trump during the coronavirus crisis' (D'Antonio, 2020). This report called for Donald Trump to step aside and to 'even go into self-quarantine for a while'. Only a few months later, Trump himself released a video on Twitter explaining that he is now the person learning. Having tested positive for the virus and received treatment, he discussed how he learned a lot about Covid. I learned it by going to school, the real school. This isn't the read the book school. I get it. I understand it' (Trump, 2020). Despite this personal declaration, it seems that what was learned through experience was not applied as others might have hoped. Trump staged 'an "insane" surprise drive-by visit to supporters outside the Walter Reed military medical center', where the president had been treated, placing others in the car with him at unnecessary risk of infection and obliged them to also quarantine for 14 days (Luscombe and Sullivan, 2020). Learning from experience then is intensely personal. Positionality concerns the values and prejudices we each hold and how we construct meaning to alter, or be altered by, such power relations. A positional perspective on learning is drawn from personal and historical experiences and changing contexts. As illustrated here then, one person's positionality on a topic such as Covid-19 will differ considerably from others. 
Also, at the time of writing, students in the UK (and in many other cities around the globe) are persistently hitting the news headlines as potential spreaders of the Covid-19 virus. As cities seek to keep their cases low, the language of signage, such as 'shield our city' (Figure 34) makes the bold claim too that 'distance makes us stronger'.

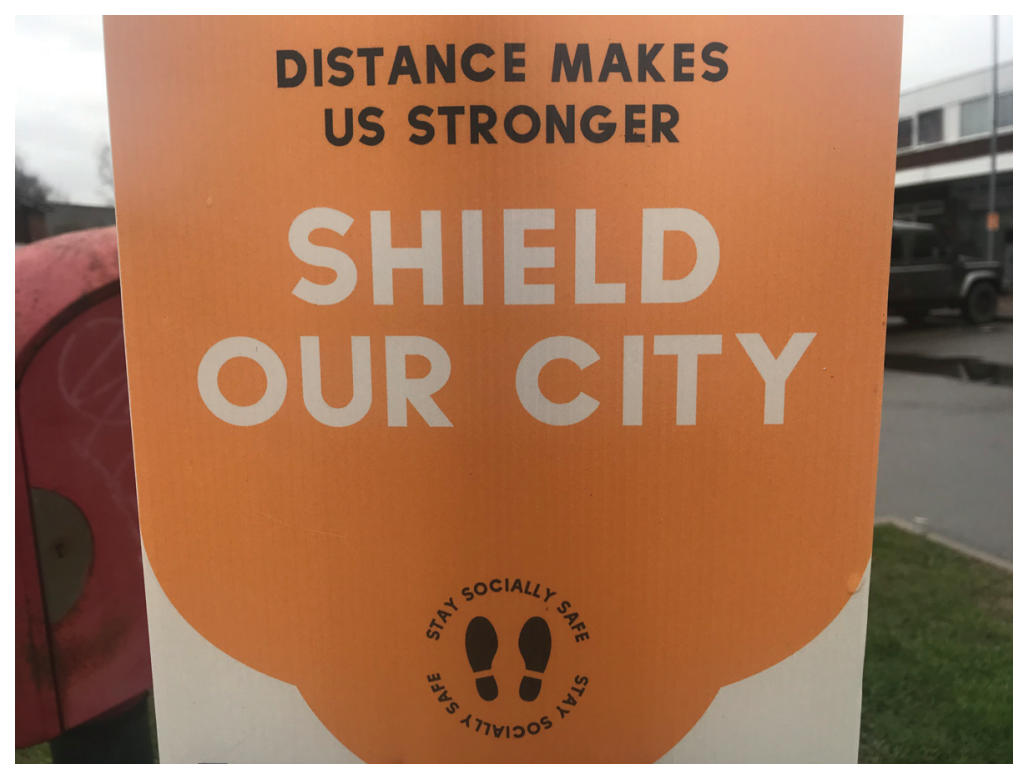

FIGURE 34 A 'shield our city' sign proclaiming that: 'distance makes us stronger'

We are not told on what basis this is believed to be true. Students are in a rather different set of circumstances to those of a US president, but they are still experiencing various forms of public criticism across the virtual airing cupboard too:

Whoever thought it a good idea to disperse 2 million Covid super-spreaders across British cities this month? (Jenkins, 2020)

Aside from the realities that some university courses cannot be conducted entirely online (for example those that require work in laboratories, hospitals, industry, stadiums and even at sea) the return of students to campus during Autumn 2020 raised a complex situation. Not only were university campuses reported as key sites of localised Covid-19 outbreaks, students were instructed to self-isolate in their halls of residence and reacted in different ways to being 'caged' (Arundel, 2020). Given that McDonaldised university campuses have in recent years come to resemble leisure and hotel complexes, as they have mimicked other forms of consumer services, students are hardly now experiencing 
the 'educational consumption' (Ritzer, 2005) that they were promised. Yet in late October 2020, universities had little time to edit their messages of welcome to students on institutional websites:

World-class facilities. Beautiful campuses. A city that is full of life and buzzing with culture, sport and nightlife. All this makes for a student experience you won't find anywhere else. (University of Nottingham, 2020)

Below this warm greeting is a Coronovirus update, as simultaneously, Nottingham was moving into the 'very high' Covid-19 restrictions (Nottinghamshire County Council, 2020). With warnings too that they may not get to return to their family homes during the Christmas break, students across the UK were understandably questioning why they were encouraged to attend campus at all. These events gave rise to a new set of HE iconography in the UK, as students decorated their windows with appeals to the general public about their plight. Where once there may have been an expensive etching of disembodied words like: 'ambition', 'impact' or 'excellence', such objective icons were covered by rather more subjective appeals revealing personal positionalities. Appearing in the windows of university halls of residences were home-made signs referring to the sizable fees paid by students as they asked: ' $9 \mathrm{k} 4$ what?.' Others pointed to their concerns of claustrophobia and mental health deterioration, alongside SOS messages and more whimsical images of beer and requests for food supplies (Rao, 2020). This was not quite 'the student experience' that has been so heavily marketed by universities on their websites during much of the last two decades and written into so many HE policy documents. These are though striking visual reminders that students never were a single, generalised body to whom universities delivered 'the student experience' to (Hayes, 2019a), despite claims like these repeated across many policy statements:

It is the responsibility of every member of the College to help develop and deliver an exemplary Student Experience. (St Patricks, 2015-2017)

In contrast, the current circumstances of many students are anything but exemplary:

From overcrowded lecture halls in France to a ban on sleepovers in Ireland, special coronavirus apps in the UK, snitching on dorm parties in the US and shuttered campus gates in India, students face a range of experiences when - or if - universities reopen. (Carroll, 2020) 
In this chapter I will firstly, provide a little further background on the increasingly irrelevant discourse of 'the student experience' that has developed as a generalised buzz phrase in HE policy and intensified following the introduction of tuition fees in the UK (Dearing, 1997; Browne, 2010). Though marketised discourse can be noticed globally in university policies, in the UK context, a strong emphasis on a particular form of 'measurement' of HE activity reveals many misconceptions of what can be actually be quantified in a postdigital society. An educationalisation of many social issues into universities has now reached a crisis point. This is demonstrated by recent attempts to house all aspects of inclusive practices in institutional policies and then to attempt to deliver aspects of these back to students, as part of 'the student experience' package deal. In a year when pre-university students have seen their exam results placed at the mercy of algorithms, students arrived at university to find themselves confined to rooms on campus and were then told there is no guarantee they can return home during holidays, a review of 'the student experience' discourse and its isolation from realities is needed. It was already overdue. Alongside an urgency to review HE policy rhetoric to be a more inclusive discourse in itself, there is a pressing need to also recognise:

the profound and dynamic impact of artificial intelligence (AI) on societies, ecosystems, and human lives, including the human mind, in part because of the new ways in which it influences human thinking, interaction and decision-making, and affects education, human, social and natural sciences, culture, and communication and information. (UNESCO, 2O2OC)

How we come to recognise these changes, in relation to human empowerment in learning, or simply as displacement of people whilst technology 'enhances' is part of this ongoing debate. What Covid-19 has also revealed is that in the communities surrounding universities there is still considerable digital exclusion. As educational institutions, agencies and charities have responded to the crisis they have discovered a lack of devices, connectivity, spaces in which people might work and learn, a lack of skills and confidence and other barriers to inclusion. Nor is this a static situation as people lose work, cannot feed children and cannot access online services to seek support, let alone learning.

Rather than take a reactive approach, with universities continuing to write a separate policy for each individual 'issue' that arises in these times of profound change, more critical and ecological approaches are required. These concern both the promises and ethical challenges of AI, as it comes to take up its place across the whole range of lifelong learning, human wellbeing and education 
(Eynon, Davies, Salveson, 2018). Suddenly 'the student experience' (whatever this may be) is orderable as a takeaway from many more places than universities. Learning requirements can be personalised for each individual. Therefore, to be distinctive as institutions, universities will need to offer something less instrumental, narrow and process-driven (Eynon, Davies \& Salveson, 2018). This moves the focus away from a collection of student data by each institution, focused on 'measuring', towards a more individual focus, where a learner's data will follow them on their life wide journey of learning what is needed, at the time it is needed. Positionality steps forward, and the instrumental marketing of 'the student experience' as a generalised product, moves off the menu.

Universities in collaboration with cross-sector agencies can though, take the initiative on this. Not as another player in the hospitality sector which has struggled so badly through the pandemic, but as a leading authority in the production and communication of knowledge. The debate on postdigital positionality needs a chair. As Delanty argued in 2001, the university needs a new unifying purpose which is not 'dominated by either the institutional context or by a reductive understanding of knowledge as information' (Delanty, 2001: 154). Policies can no longer sit apart from each other or the wider postdigital context surrounding universities. However, 'neither 'cultural politics nor the market offer a principle of unity' (Delanty, 2001: 151). The new global emphasis on sustainability and education just might do (UNESCO, 2020d). Delanty argued that as the university has lost its status as the sole site of knowledge it has become 'more and more drawn into the communicative structure of society' (Delanty, 2001: 152). Universities are therefore able to explore a new positionality of their own in postdigital society as biodigital philosophy, technological convergence, and new knowledge ecologies begin to emerge (Peters, Jandrić \& Hayes, 2021a). I will return to these possibilities in later chapters. The implication for those learning though, is that, as diverse individual citizens, they will have greater choice of routes to learn and to further personal and collective goals. As students who learn in universities and take up roles in society relating to their discipline, they are entering diverse, fluid and changing work contexts. The critical reflexivity to appreciate their positionality in this postdigital landscape is key to their empowerment, rather than their displacement.

In the second half of the chapter I will examine this alternative to the current approach, where an overly inflated and generalised experience is discussed as the main attraction on the campus 'menu'. By applying the tenets of positionality, as put forward by Torres, Olave and Lee (2019), it becomes possible to notice just how different each student's individual experience is likely to be in a postdigital society. At a time when many larger areas of life (cultural, historical, technological, biological, political and economic, for example) can be 
observed to be merging, converging and overlapping in our postdigital global context, what individuals encounter through their own positionality, seems to be more diverse than ever.

It is therefore necessary to counter a strong suffocating marketing rhetoric of a generic 'student experience' with a more autonomous approach where each citizen recognises the possibilities before them. There are a number of authors who have begun to refer to personal 'learning ecologies' (GonzálezSanmamed, Sangrà, Souto-Seijo \& Estévez, 2020, Fawns, Aitken \& Jones, 2020) because these offer 'self-directed' ways to update personal knowledge and capabilities at the point that this is needed. This alters more traditional models of the labours of learning and teaching. However, digital advances that have brought AI into education, with chatbots and automated functions replacing teacher activities might also be discussed as developmental of both student and teaching roles. Very often rational McPolicy sets up an oppositional relationship between those learning and those teaching when they may in fact become more closely constitutive of each other, in some cases. Considering how student identities are complex, fluid, enmeshed in power relations and contextually bound offers new possibilities for inclusivity agendas that actually connect students and teachers as individuals. This requires a shift from delivering an assumed 'mass experience' that teachers are audited on, in terms of their efficiency, towards new appreciation of diverse postdigital positionality. Though students may feel somewhat 'caged' right now, there are possibilities ahead where we no longer need to detach the cultural, technological and biological wellbeing of students or teachers from all aspects of their lives or from the wider community. What is missing currently is a convergence of $\mathrm{HE}$ policies to recognise these interconnections.

Over recent decades in universities, as audit culture has taken hold, students have become rational objects of study in university policy, rather than individual human subjects, who study their chosen subject disciplines from their own diverse positionalities. In UK policy and more globally, students have become defined for some time now as 'customers', particularly since an introduction of tuition fees (Dearing, 1997; Browne, 2010). Customer 'experience' gets routinely evaluated, but this reduces knowledge to information that is easily processed as data. Universities are using the processing power of computing to construct the identity of the students that they admit, in a reductive 'measurement' of access, participation and success, via audits such as the Teaching Excellence 
and Student Outcomes Framework (TEF) (Office for Students, 2019).Yet the implications of this datafication cannot be separated from the related ontological and epistemological dilemmas that accompany it (Van Dijck, 2014).

Presently, universities have restricted their enormous capacity for critically reflexive dialogue about knowledge to one limited by, and obsessed with, institutional information. Furthermore, at the same time as attempting to address every imaginable issue any student might encounter by generating endless policy information, universities are adding to potential issues of bias, as they trust student data to corporate platforms. University policy cannot be said to uphold social justice if the commercial values surrounding data collection, use and any hidden design and programming processes that reinforce existing inequalities are not transparently examined. This requires a critical appraisal of the ideology behind the 'whole ecosystem of connective media' (Van Dijck, 2014) that universities have bought into.

University policy focusing on inclusive practices for students does sit apart from social media, the corporate platforms that universities have adopted, or any flawed approaches towards collecting and measuring student data. In postdigital society, interpersonal communications are mediated by platform capitalism and big data. As part of these networks universities have expanded their data infrastructure and performance metrics and are becoming experimental sites for commercial AI systems (Williamson, 2017, 2019b, 202ob, 2020c). During the Covid-19 pandemic new commercial edtech partnerships have accelerated these developments but with little time to critically examine where this shifts the power.

\subsection{Inclusivity Is More Than an Item on 'the Student Experience' Menu}

There is now a pressing need for critical dialogue that takes a different starting point on university equality, diversity and inclusion policy from the assumption that such principles have already been 'embedded'. It is not enough for universities to simply act like another branch of the hospitality sector and add these into 'the student experience' menu. As part of the ecosystem of communicative media (Van Dijck, 2014) in postdigital society, the university now needs a strong sense of its own positionality. This requires fundamental changes to the routine generation of isolated McPolicy.

In The Labour of Words in Higher Education (Hayes, 2019a), I argued that through related HE policy discourse (McPolicy), we appear to have constructed an iron cage of 'the student experience' (Hayes \& Jandrić, 2018). I demonstrated through a corpus-based Critical Discourse Analysis (CDA) of policy documents how this package of 'the student experience' can also appear to 'act' to achieve things, concealing also the labour of the diverse humans who work 
with students in universities. My analysis showed how this linguistic positioning of students has contributed to both detaching humans from their own labour and 'a separation of the labour of teaching from the labour of learning' (Hayes, 2019a: 20). For a more detailed explanation of corpus-based CDA, see Hayes and Bartholomew (2015) and Hayes (2019a).

In placing huge emphasis on learning experiences in isolation from teaching and research activities this reconceptualising of students has not only culturally divided the university, it has led to a 'therapeutic' turn (Ecclestone \& Hayes, 2019) also dubbed a 'snowflake' culture. So whilst on the one hand, many authors have critiqued the 'student-as-consumer' approach in HE policy (Molesworth, Nixon \& Scullion, 2009, Bunce, Baird \& Jones, 2017, Peters, Jandrić \& Hayes, 2018) for treating education as a customer transaction, other authors have discussed how this has led also to a rhetoric of students as weak or defenceless (Furedi, 2016). However, if a rationalised experience is constructed on behalf of students, then universities align themselves with any other provider of consumer experiences, where the thinking has all been taken care of for students. In such a discourse, students are not necessarily conceptualised as empowered consumers either (Brooks, 2017) but are trapped instead within an 'iron cage', even before they set foot in the workplace. Students' 'vulnerability is emphasised by both government and unions' (Brooks, 2018: 745). This has its uses too because it can deflect past failures by governing agencies to address inequalities, if the spotlight remains on students as deficient. This now sits uncomfortably though, alongside scenes where (if students are thought to be vulnerable) they were encouraged onto campus, detained in their rooms, had limited social contact due to Covid-19 restrictions and were prevented from visiting parents, if homesick or in need of support. Rather than viewing Covid-19 as a hiatus, it may be useful to view it as exposing institutional policy weakness.

\subsection{Student-Centred Culture}

A rational 'student-centred' culture (Hayes \& Wynyard, 2002, 2016) can sound like a positive development that is difficult for staff or students to question. Statements like 'placing students at the centre of all that we do' is a common line that is found in university policies following an increased marketisation of the sector. This has though also proved to be a far from empowering rhetoric in practice (Jarvie, 2014, Furedi, 2016, Ecclestone \& Hayes, 2019) as an emphasis on pedagogies for student-centred learning (O'Neill \& McMahon, 2005) has become conflated in HE policy with the problematic notion of 'the student experience' (Hayes \& Jandrić, 2018). There has been a tendency in policy discourse to discuss access to HE for particular groups of people in ways that can overlook complex 
social phenomena and further only narrow, therapeutic agendas (Ecclestone \& Hayes, 2019). For example, much has been written concerning the important aspects 'of belonging' or 'wellbeing' as a student in HE. However, these campaigns can sound as if issues are being addressed by institutions alone, rather than in a two-way flow, where students themselves are active in shaping institutional understanding too. The levels of belonging that individuals choose to opt into are also relevant when such choices may be based on many different facets of a person's identity. HE policy has a tendency to focus only on a single aspect of a person's identity, such as their gender or their race, which limits understanding concerning the fluid 'intersections of race, class, nationality, gender and sexual orientation' (Wheaton \& Kezar, 2019: 65). Such fluidity suggests that aspects of our identity are processes, rather than conditions (Dixson, Trent, Ladson-Billings, Anderson \& Suarez, 2020), and so subject to new dynamic understandings related to social and historical contexts and change.

Terminology in social theories about learning can come to mean different things to different people, but this can also be the basis for interesting critical pedagogical debate which reveals complexities regarding the positionality of individuals. This could concern for example the differences that teachers perceive between experiential learning, self-directed learning or other flexible forms of pedagogy (O'Neill \& McMahon, 2005). Whilst the experiences of students could be very different in each of these scenarios, the use of the term 'the student experience' has taken on a much larger overall presence, beyond debates about learning in university policies. It has come to act as an expanding container for many social issues to be placed under, but rather like my airing cupboard in the hall, it has become overly full and it now needs a clear out.

\subsection{The Student Experience McPolicy Discourse}

A key critique levelled at this phrase is that it has come to embody the notion that students paying for their education are purchasing a package they can consume, just like any other McDonaldised service. What this McPolicy discourse closes down, due to a singular objective construction in: 'the student experience', is the opportunity in policy for students to be discussed as diverse individuals and for them to input that diversity back into policy. The student experience is a linguistic construction that firstly, has emphasised the role of a degree as a consumer 'product' purchased to secure future employment (Peters, Jandrić \& Hayes, 2018), rather than an experiential learning 'process' with transformative potential that continues well beyond student life (Hayes, 2015: 130). Secondly, a narrow understanding through a student-as-consumer approach in HE policy has developed into a strong rhetoric emphasising 'the 
student experience' as a package deal (Hayes \& Jandrić, 2018). The impression generated is that universities are delivering a broad packaged experience of consumption itself, to students (Argenton, 2015: 921). This assumption has recently swelled further still to incorporate a range of egalitarian ideas, such as fairness, justice, equality of opportunity, diversity and well-being, but it is a fallacy that these can be packaged up for delivery in this way. Exactly what experience is being delivered and based on whose values?

In a document published by The Higher Education Academy (HEA) entitled: Managing the student experience in a shifting higher education landscape (Temple, Callender, Grove \& Kersh, 2014), it stated:

We describe the student experience as the totality of a student's interaction with the institution.

What though, if the 'totality' of each individual student's experience is constructed through multiple, mutually constitutive factors that do not cluster within the gates (or control) of an academic institution? What if the decision to accept considerably more students into university (based on predicted grades following the backlash from algorithmic predictions) has left many new students ill-prepared for what degree studies will require from them? Add to this situation unequal access to digital equipment (when trapped in student accommodation with no chance to physically visit the computer rooms, library or laboratories on campus) and it is not hard to see how these circumstances, due to a biological threat, can mingle with other existing disadvantages.

Universities responded to support students with food parcels and financial compensation, but it is challenging to also attend to their anxieties, diverse needs and the expectations of each student. The demands already placed on personal tutors will have increased in complexity. Even without the Covid-19 pandemic complicating the social, economic, educational and technological circumstances of each student's interaction with the institution, there is still huge variation in positionality amongst students. What defines each student's interaction with the institution in postdigital society does not remain static either. The pandemic has laid bare the problems with an approach to HE policy that seeks to 'embed' everything from digital platforms to wellbeing, inclusivity and even student ambitions, within institutions:

The purpose of this Student Experience Strategy is to deliver the student experience ambitions of Edinburgh Napier University as set out in Strategy 2020. (Napier University, 2020: 3) 
Statements like this help to draw attention to the issues of seeking to control everything that students now experience under university 'ambitions', as if these were internally consistent for the place of study and for each student. The diverse experiences and ambitions of students from all walks of life do not exist only within a walled university garden controlled by the staff therein:

It is vital that every member of staff fully understands their contribution and that of their colleagues in delivering the Student Experience. (Hayes \& Jandrić, 134 :2018)

Placing aside for the moment the problem that individual staff contributions to a generic idea of 'the student experience' cannot easily be separated out to be quantified and measured, the emphasis on 'delivery' by an institution has long been a problematic concept too. The diverse experiences of each student cannot be ordered from the university, delivered and rated, as if sent out by any other commercial provider, such as Amazon or Argos, with the follow-up question: what did you think of your purchase? (Hayes \& Jandrić, 2018). As students currently confined to their rooms in lockdown have discovered though, right now it seems easier to get a free Deliveroo order through, than to access the 'package' of higher education they have paid such high fees for:

Students can also use the Morrisons on Amazon service which includes free same-day delivery and Morrisons service on Deliveroo. (Morris, 202ob)

In these unusual times, examples of this kind help to illustrate why a rational university policy discourse of delivering 'the student experience' remains an irrational claim for institutions to make. It is a problematic buzz phrase, but one which has also had its uses: 'as a construct to which all manner of expectations can be attached (Hayes, 2019a). Indeed, the educationalisation of social issues as problems for universities to solve, seems to be a defining feature of our times (Peters, Jandrić \& Hayes, 2018). The concerns themselves may be ill-defined, ranging from mental health and wellbeing to transport and support from animals on campus, but still they have powerfully re-shaped popular understandings of 'the student' and their role in HE (Hayes, 2019a). A reconceptualisation of students has been achieved in part through this therapeutic turn, which according to Apperley (2014), includes:

Increased emphasis on the student experience, signalled in part by the rhetoric of student-centred education, but also by the forced emphasis 
on universities as 'learning institutions' as opposed to teaching institutions. The idea that universities might be educational institutions involving both learning and teaching has increasingly been suppressed by these rhetorical strategies. (Apperley, 2014: 732)

I will return to this separation of the labour of teaching from the labour of learning in the next chapter, but as one of the casualties of marketisation, it has brought both increased academic workloads and what Furedi argues is a 'deficit' model of students, within an infantilised university (Furedi, 2016).

\subsection{A Victimisation of Students}

From a 'Disneyfication' of academic courses, and ultimately to the preservation of the elusive and burgeoning notion of 'the student experience' (Hayes, 2017: 106), it has been suggested then that such factors have actually turned students into 'victims' (Furedi, 2016: 9). This is because the 'experience' generated is based on 'a diminished view of human subjectivity, which regards individuals not as agents of change, but as potential victims of the circumstances they face' (Furedi, 2016: 9). Furedi pinpoints the issue with this discourse where 'rhetorically, it preaches the value of diversity; in practice, it refuses to tolerate a diversity of opinions' (Furedi, 2016: 9): hence the concern that as cancel culture has grown in society it seems naïve to imagine that (like any other concern) it can simply be added to the list of social issues we 'educationalise' into school and university inclusivity policy.

Furedi points to a paternalistic form of governance (Furedi, 2016) which is behind the victimisation of students. This is echoed by Bartram, who suggests that the UK Teaching Excellence Framework (TEF) has also cemented a 'consumerist machismo' via a 'fetishisation of satisfaction' (Bartram, 2020: 6). Furedi contends that therapeutic culture requires continuous intervention, whilst Apperley suggests that against this background, 'public policy - including that of education - must be redirected towards shoring up the emotional deficit of the individual' (Apperley, 2014: 734). Analysis by Brooks (2017) of how students are now constructed in contemporary English HE policy supports these concerns. Whilst students may be assumed to be 'empowered consumers' in today's commercially driven universities, their vulnerability is emphasised in policy by both government and student unions (Brooks, 2017: 1). This then feeds into broader government narratives, legitimising contemporary reforms and excusing apparent failures of previous policies (Brooks, 2017: 1, Hayes, 2019a: 35). There is considerable difference though between knowing cohorts of students well and building important connections with them as a teacher, and the victimisation culture that has trapped students in a 'cage' of 
weakness, vulnerability and dependence. The Covid-19 crisis has brought such dynamics into the spotlight as well as demonstrating striking knock-on effects across different levels of the educational sector.

\subsection{Training Key Workers of the Future}

As universities have donated equipment and laboratories to support the pandemic effort, as well as sent many of their trainee health professionals into frontline work, there are calls to protect and sustain university programmes which meet the need for key workers of the future. There are though many aspects of the broad landscape being referred to as 'key work' that the pandemic has also brought to public attention.

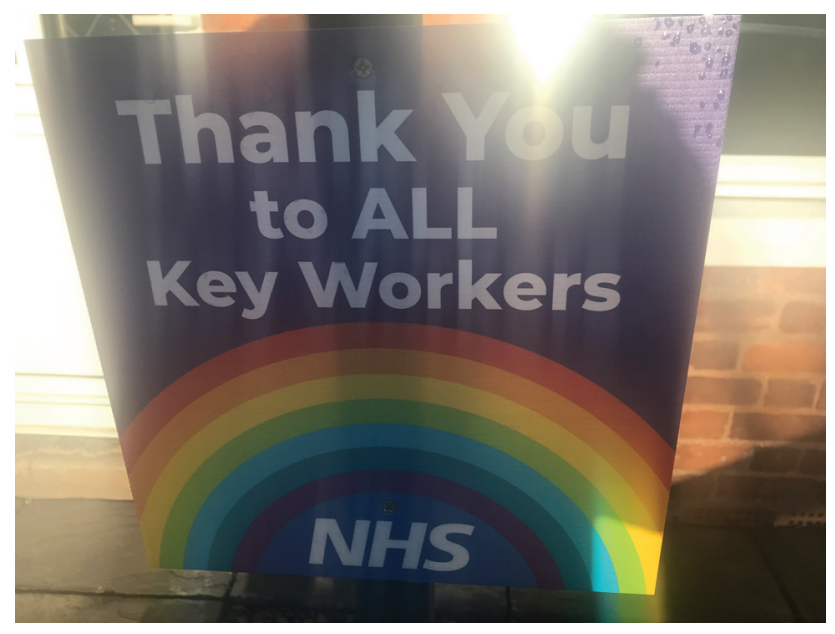

FIGURE 35

A sign with a rainbow

thanking all key workers

Whilst health and care workers immediately come to mind (Figure 35), there is a broader spectrum of essential workers whose labour might be considered 'foundational' given that it can't be shut down (Foundational Economy Collective, 2020). Many people working in cleaning, delivery and supermarket roles, as well as those in education, care and health services may also be a part of the 'gig economy', on precarious or zero hour contracts, facing economic risks and potentially high levels of stress, whilst working through the pandemic. As many graduating students enter the harsh conditions of the gig economy and take up key roles, even temporarily, there are risks if their treatment in university has emphasised only their weakness, vulnerability and dependence.

Even for highly trained medical professionals, new challenges have emerged as frontline, lifesaving healthcare environments have intermingled with aggressive forms of cancel culture in the virtual airing cupboard. As Rachel 
Clarke's 2021 book: Breathtaking: Inside the NHS in a Time of Pandemic attests, nurses and doctors are now facing physical and virtual forms of abuse from Covid deniers and sceptics denigrating their work and even trying to physically remove sick and dying patients from wards (Clarke, 2021). A generic policy discourse of 'the student experience' is inadequate and inaccurate as universities plan to train key workers for the future. New policies will be required that reflect the multiple changes to workplaces where students undertake placements and seek to develop their careers.

\section{6 'Learning Never Stops' But My Future May Be Decided by an Algorithm}

The \#Learning never stops campaign (UNESCO, 2020a) provides further individual insights from around the world through the UNESCO Associated Schools Network. The quotations and comments from school students, teachers and parents describe the pressing need for personal contact between staff and students, when teachers know their student's backgrounds, strengths and weaknesses. They discuss the use of every possible form of communication when many students are without computers or laptops. Teachers say that they feel they are now working all of the time and they describe concern too for their own students' mental health. Parents add their concerns about whether their children are learning sufficiently at home and there is of course considerable anxiety over exams (UNESCO, 2020a). These audible and readable accounts from different locations mean that many aspects of what it means to learn and teach through the crisis and from home can be noticed.

Even as lockdowns are eased, accounts of what it means to run a school and seek to control social distancing take their toll on staff and students, as in this anonymous headteacher diary of the shape just one week took at the beginning of term (Guardian, 2020c). This is indicative of so many accounts and testimonies that have been shared by individuals online. The physical symbols of lockdown discussed earlier have made certain things visible, such as the chalk drawings on homes that reminded us that children were not at school and the many lists of rules that have appeared detailing various 'steps to safer working together' (Figure 36) or 'stay safe' rainbow trails (Figure 37).

Yet there are other less visible new partnerships in the lives of students seeking to complete their studies, move on to university and plan their futures in these challenging circumstances. The complex interplay between viral biology on the one hand and information science on the other, can be clearly observed in the A level algorithm example as this played out in the UK during Summer 2020. Many computer algorithms use statistical models, to good effect. For example, they are used in pharmaceutical trials, in order to test the 

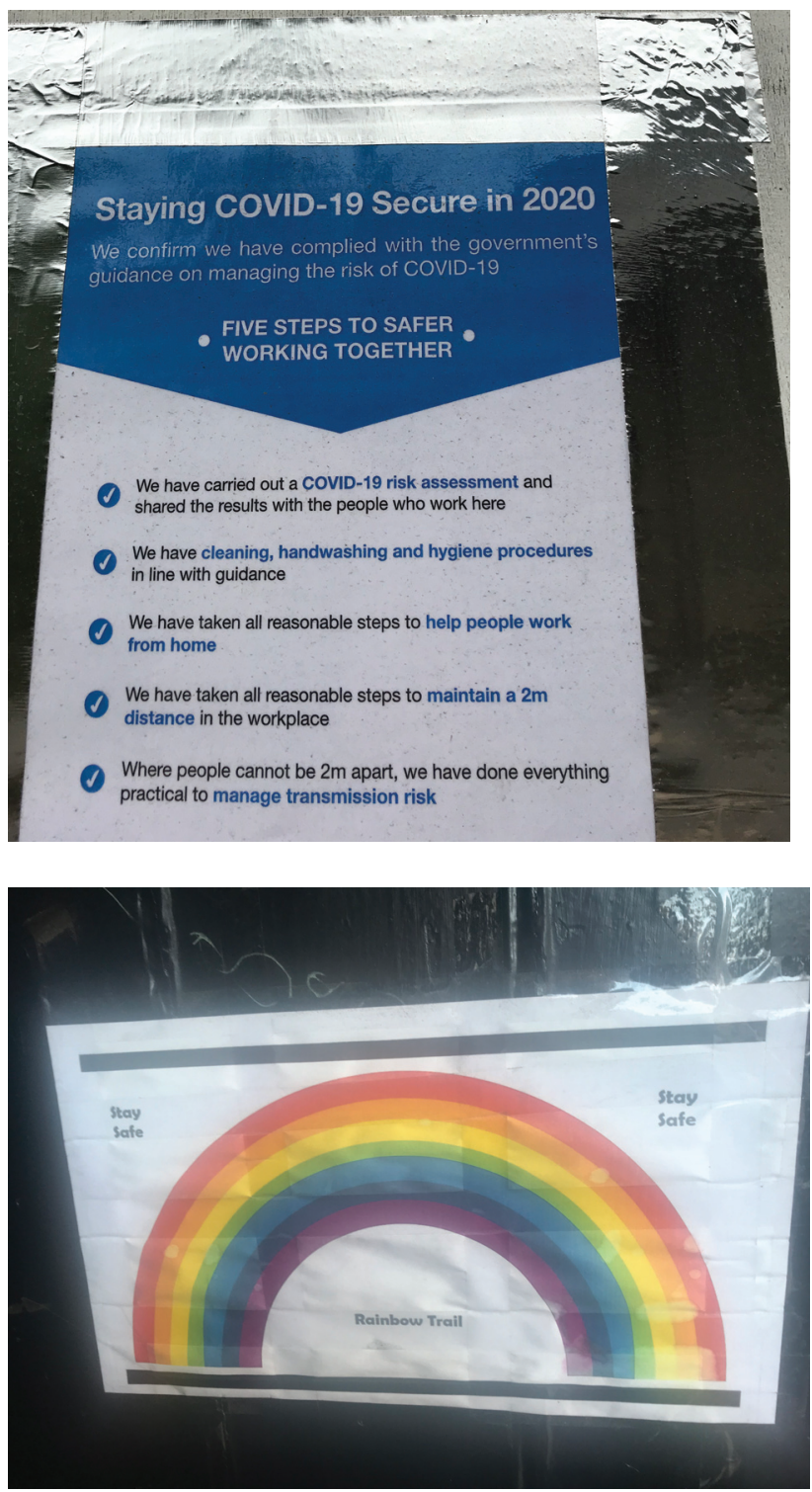

FIGURE 36

A staying Covid-19 secure sign detailing five steps to safer working together
FIGURE 37

A 'stay safe' sign as part of a Rainbow Trail

effectiveness of a new drug. Typically, the drug is tested against a control, since it is the systematic difference between the performances of the drug and the control group that must be evaluated. The statistical models, inherent in the algorithm, enable this systematic difference to be separated from the natural variation that is always present. In a very real way therefore, statistical models can save lives.

The use of such statistical algorithms can, though, be more controversial as observed in the recent move to deflate A'level, GCSE and other predicted 
student grades. The moderation of grades from public exams has always been part of the quality assurance process. The aim has been to ensure parity between different educational institutions and uniformity, and where possible, between year groups. The requirement for such a process became critical though when, due to a government decision, no final exams were taken in the Summer of 2020. Predicted grades, supplied by teachers, have always been a requirement, prior to exams in general. They have tended to be the basis of appeals too, for example when a student has been absent, through illness. The predicted grades for the summer of 2020 were though significantly higher than the corresponding examination grades had been in previous years. This was not unexpected and historic data was used to redress this perceived imbalance.

It is understandable though that individual students would feel aggrieved that their predicted grades had been reduced when they had not had an opportunity to sit any exam. The situation was made somewhat worse however when reductions in grade appeared to lack uniformity between various institutions. Students from lower performing institutions appeared to have been affected worse; presumably historic data suggested that the disparity between predicted grades and actual grades was more marked in some institutions than in others. There also appeared to be bias built into the algorithm and the situation soon became untenable. To put these events into another context, it could be asked: what boxer, athlete or sportsperson would accept an adverse outcome from a virtual, computer-modelled contest, when deprived of the opportunity for a real competition? How much more aggrieved would they feel if the algorithm had used their postcode to predict the outcome? Of course, such a sporting analogy is not quite the same as using historic data for deflating overly high grades in education. No one places all sportspeople under one blanket discussion of 'the sporting experience' either.

So whilst using historic data was seen by some to be an objective part of a valid quality process, once the data was in the public domain, the use of such an algorithm for assessing grades was open to ridicule, mass dispute and protests from students and teachers:

We don't sentence people for crimes committed by someone else, so why sentence students to grades someone else got in the past? That's exactly what the Government has done with its disgraceful approach to A levels. (Payne, 2020)

Whilst the mantra of Trust the Teachers was adopted as an appealing slogan, it is not quite obvious as to what they should be trusted with. The inflated aggregate grades remain for this year at least, with all of the consequences this may 
have, both for those who have since left for university and for those who did not take that route. There are those who argue that the 'exams fiasco is just the beginning' and that it was both absurd to attempt to 'determine individual attainment by computer model' or to think that 'teacher-predicted grades are any substitute for proper examinations'. Either way, each of these 'panicked responses to the coronavirus' is likely to 'cause one injustice after another' (Slater, 2020). What can be learned though, is that 'people want individual results' and the anger of both physical and online protests attests to this. Positionality comes into play as people are mostly concerned with their own individual results and fairness of them. They do not want to be the 'result of an aggregate' (Burgess, 2020).

\subsection{The Student Experience Policy Discourse Lacks Inclusivity}

Whilst no educational system can claim to be entirely fair for everyone across the board, the treatment of diverse students in this rationalised manner resulted in uproar. Sabri (2011) has argued that not only does 'the student experience' rhetoric homogenise students, depriving them of agency at the same time as purporting to give them a 'voice', it is potentially also 'a means of discriminating between the value of different experiences of education' (Sabri, 2011: 657). Regulators of HE (such as the Quality Assurance Agency and Higher Education Academy, but more recently, Advance HE and the Office for Students in the UK) have helped to established this discourse, but it could also be said to be performing a line of 'work' itself: 'in sustaining and developing the market-oriented disciplining of higher education' (Sabri, 2011: 657). Sabri adds that this has come at a price, because:

the sacralisation of 'the student experience' has in fact obscured the educational form and function of experience for an ethnically and socio-economically highly diverse body of students. (Sabri, 2011: 657)

It is in this situation that the rational and seemingly empowering mantra of 'the student experience' has become increasingly irrational. Inventing, labelling and packaging this as a 'product' and delivering it to universities for a response may have given it the appearance of a concrete existence. It has though, served to mask the individual experiences of students of the equality, diversity and inclusivity agendas, that institutions are now scrambling to deliver.

The policy statements in which 'the student experience' is frequently embedded, sound as if everyone should believe that this is how the world of universities works. Instead of treating human identity and senses as personal and diverse, the policy discourse discusses what each student encounters in 
terms of generic ideas on 'belonging' or 'involvement', as if these were collective, not individual, and thus experienced uniformly by all. Such problematic assumptions even suggest that 'a sense of wellbeing' is included in 'the student experience' deal that gets delivered to students. As such, academic experience has become interconnected with all other experiences, but treated as if it were any other generic adventure or leisure deal on offer at a local hotel (Hayes \& Jandrić, 139:2018). It is therefore not difficult to see why the students caged in their rooms currently are calling for their money back!

\subsection{Some Students Feel Like They've Been Scammed}

The is how one student described how they felt in relation to the promises of 'the student experience' in a year when this package is proving even harder for HE to 'deliver':

The experience we're getting simply doesn't match up to what we were promised before arriving at Uni this year. Within the months prior to term starting, we received an array of polite emails from the Uni expressing their acknowledgment of the "current situation" and how they were doing "everything in their power" to make sure we have an "amazing experience". What a load of rubbish that was. (Arundel, 2020)

Other students added that they would have deferred if they had known the realities, mentioning that they 'felt robbed' and had 'been forced into something without our consent'.

It seems many students, like me, feel scammed by false promises of a "close to normal" experience. We've walked right into what feels like a trap: get students to Uni, tell them it's all going to be sunshine and rainbows, then tell them they can't leave their bedrooms. (Arundel, 2020)

It is clear from student accounts like this that even one face to face class a week would be welcomed under the current circumstances and that human contact is needed:

Now, more than ever, we need to be able to contact our professors when we need them. I appreciate that online learning is stressful for staff too, but the most depressing part about it is that, although the Unis are trying to "deliver a high quality of online learning", many students are reporting their emails aren't being replied to by lecturers, leaving them left without access to the tuition they are paying for. (Arundel, 2020) 
Though the pandemic could not have been predicted by universities, perhaps it will yet provide a portal through which institutions might distance themselves from the policy fallacy of 'the student experience'. When each of us is instructed: 'keep your social distance' (Figure 38) this is not one collective 'experience', but rather it plays out as an understanding that each of us has to individually navigate. For some this is likely to yield trauma, panic, emotion and fear. For others it may be more of a relief, or something to endure

Finding 'space' for debate on more ecological approaches (Bronfenbrenner, 1994, Fawns, Aitken \& Jones, 2020) than 'the student experience' rhetoric is necessary, where positionality not assumed generic knowledge, is central to addressing inequities in postdigital society.

\subsection{Debating Ways to Address Inequities through Postdigital Positionality}

As an intensely 'studied' group of people, students in universities have been categorised in all sorts of ways in recent decades. Jones (2010) has questioned, 'so just what is the student experience?'. In a literature review examining various conceptual frameworks, he states:

Paradoxically while there are many studies that consider aspects of the student experience, there are very few which attempt to define it. (Jones, 2010)

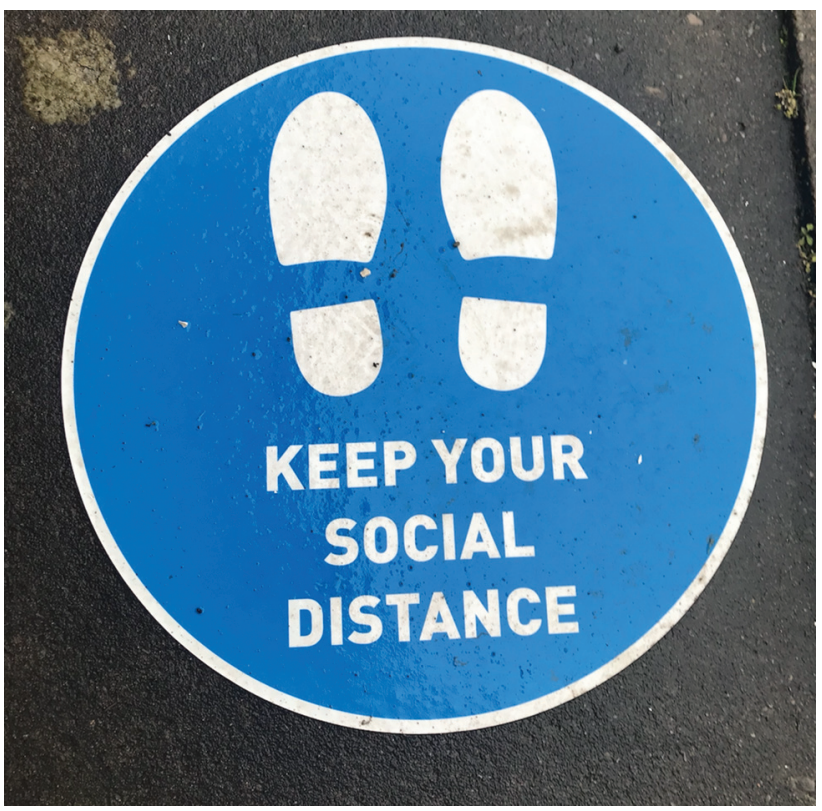

FIGURE 38

A 'keep your social distance' sign 
Examining the literature, Jones found that seven main themes could be identified: students' expectations about university and student life, transition, peers, others: parents, culture and the media, the degree programme, extra-curricular activity, what happens post graduation: employability (Jones, 2010). Jones then examined these within Bronfenbrenner's ecological model (1994) as a potential framework in which to evaluate the student experience and understand a student journey. This approach towards understanding human development is one way to begin considering ecological approaches to understanding human development. The idea of 'micro-systems' is used to examine the relationship between the individual and their immediate environments. Micro-systems may operate in the 'meso-system', which is the location of closest proximity to the individual and the area having greatest influence on their development, or they may operate in the 'exosystem', which is where further individual microsystems operate, but have less influence on the individual because of their lack of close proximity. Bronfenbrenner also refers to 'macrosystems' which are about the overarching pattern of systems and chronosystems which allow for the impact of time (Bronfenbrenner, 1994). Whilst this conception begins to map out some broader contexts interacting with individual learners, it is necessary to bring to such a framework the dynamic ways in which computing systems and data now alter human experience in new unpredictable ways.

Therefore, as well as examining student positionality in such a model, interactions with and between non-human actors in the messy and unpredictable postdigital context surrounding learners, needs to be considered. For example, our learning and inclusivity experiences are now 'flesh-electric' (Lewis, 2020) as discussed earlier. Torres, Olave and Lee (2019) argue that despite a robust literature on positionality, HE research often neglects engagement with people's varied, fluid, and complex positionalities. They suggest that personal positionality is constructed around three main tenets: (1) identities are complex and fluid, (2) they are enmeshed in power relations and (3) they are contextually bound. It is therefore worth considering how such an understanding could bring new alternative ways to understand inclusivity and to appreciate the diversity of students. This offers one way to move away from the restricted and swollen rhetoric of the student experience.

\subsection{Student Identities as Complex and Fluid}

Students are also citizens, members of communities online and offline. They may work or have family or caring commitments, a personal disability, may be studying in a different country to their own and writing in a language that is not their native tongue. Their perceived identities also intersect across fluid and changing contexts (Collins \& Bilge, 2016). As such, students have 
'multidimensional subjectivities' and complex relationships with the spaces and places they inhabit (Torres, Olave \& Lee, 2019: 6). By subjectivity, it is understood that this refers to the condition of being a person. This includes the processes through which each of us become a person. Therefore, subjectivity is about 'how we are constituted as cultural subjects and how we experience ourselves' (Barker \& Jane, 2016: 260). These subjectivities are inextricably linked with our personal values and self-identity, which are understood to concern 'the conceptions we hold about ourselves and our emotional identification with those self-descriptions' (Barker \& Jane, 2016: 26o). Closely linked to both subjectivity and self-identity is our social identity, which refers to 'the expectations and opinions that others have of us' (Barker \& Jane, 2016: 26o).

Despite the complexities described above, there has been a tendency in HE policy over recent decades to persistently objectivise student identity. Other examples beyond 'the student experience', include for example referring to an 'international student' which is another socially constructed label that may aid institutional categorisation, but also projects a monolithic and static view of the individuals concerned (Torres, Olave \& Lee, 2019: 7). Taking an approach that focuses on student positionality instead enables students themselves to identify their multiple subjectivities as a dynamic negotiation. Recognising the 'nonunitary subjectivity' (Hollway, 1989) of students is not only a more accurate, context-responsive and inclusive approach it is also one that AI in education is increasingly able to appeal to, in terms of providing personalised forms of learning.

Torres, Olave and Lee (2019: 8) discuss how the positionality of a student can additionally vary through space and time, as they adopt different roles, such as that of an expert to present something at a conference, or as a doctoral candidate to receive supervisory advice. Some students are also supervisors of others in workplaces and/or parents of children. Taking a perspective of lifelong learning, positionality shifts over time, location and changes of role alongside the countless subjective variables at play in individual identities. All of this takes place in relationships with others that are powerful and not symmetrical (Sheppard, 2002). Additionally, in postdigital society positionality is altered through a messy, complex interplay of both people and things. This brings new implications for positionality, such as examples described in the previous chapter where forms of discrimination do not only take place between humans. These can travel from human design processes into systems and data and back into further social interactions between people. These are influences that need to be acknowledged in university policymaking for inclusivity, because equality, diversity and all manner of inequalities are now intimately constructed, and reconstructed, via digital interactions with computers that can keep people on the margins (Jandrić \& Hayes, 2019). 


\subsection{Student Identities Enmeshed in Power Relations}

The power relations surrounding student identities are therefore mutually constitutive, as students either accept or resist conditions that they find themselves in. A student 'simultaneously negotiates the multiple dimensions of language, various forms of capital, as well as evolving social identities' in different contexts (Torres, Olave \& Lee, 2019: 2). However, when it comes to digital contexts where oppression is less obvious there are new power relations that affect inclusivity. Costanza-Chock (2018: 7) points out that closely linked to intersectionality is the concept of the 'matrix of domination' which refers to 'race, class, and gender as interlocking systems of oppression'. Describing factors such as power, oppression, resistance, privilege, penalties, benefits, and harms as 'systematically distributed' these will structure different people's lives in different ways (Costanza-Chock, 2018: 7).

Placing these observations in the context of data-driven AI systems it is argued that at the personal level, a student could experience an interface that either 'affirms or denies' their identity, through features such as 'a binary gender dropdown during account profile creation'. At the community level, AI systems design may foster 'certain kinds of communities while suppressing others, through the automated enforcement of community guidelines, rules, and speech norms, instantiated through content moderation algorithms and decision support systems'. Such rules may decide who is included in a protected category in relation to hate speech or certain content moderation guidelines. Then, at an institutional level there are further considerations as universities both adopt data driven AI systems for teaching but also train computer scientists, developers, and designers on courses in the institution (CostanzaChock, 2018: 8). There are therefore important considerations for universities to examine drawing on intersectional theory to reflexively look at how their own stance on inclusivity might now be undermined at different levels. This could include isolated decisions being taken concerning technologies for use in learning and research and related commercial partnerships that bring a different set of marketised values to education (Williamson, 2017, 2019b, 2020a, 2020b, 2020c). Or it may concern the design and deployment of 'AI systems that shape the distribution of benefits and harms across society' (CostanzaChock, 2018: 8).

As discussed earlier, there are many powerful influences surrounding what is being put forward by universities as an 'inclusivity' policy agenda or framework. Covid-19 highlighted the problem that large numbers of students had no laptop of their own, triggering schemes by universities to rapidly respond. However, there are the additional related challenges of wifi bandwith in shared housing and a lack of space to work. These and other inequalities demonstrate why inclusivity agendas do not sit apart either from a political digital economy 
where opportunities sit alongside dangers of exclusion (Bukht \& Heeks, 2017). Having access to a computer and the skills to use it imaginatively can bring about support from the wider community, even from celebrity benefactors. In one example, Russell Crowe donated nearly $£_{3}$,ooo to a student who could not afford to take up the place they were offered on a prestigious drama course. The student created a GoFundMe page in an effort to raise the necessary cash and caught the attention of the film star (Zahid, 2020). Not an isolated incident, when only the previous week, Taylor Swift had donated £23,0oo to a different student so that she could afford to attend a UK university (Sky News, 2020). These instances are part of wider ecological streams of communication and activity in the virtual airing cupboard, but they are not accessible by all.

Assumptions made in policy are problematic when they are not cognisant of these intimate flows of knowledge passing between humans and computers in the form of bioinformational capitalism (Peters, Jandrić \& McLaren, 2020) and feeding into the positionality of each student in different ways. These are not scenarios that can be educationalised, but this is a dynamic context that requires honest and inclusive critical representation in university policy, to acknowledge that student experiences are plural, unequal, and contextually bound.

\subsection{Student Identities as Contextually Bound}

Torres, Olave and Lee (2019: 22) point out that any student or scholar's 'selfunderstanding is mutable and context-responsive'. This means that the selfconceptions students hold and their emotional identification with these are subject to multiple influences, including those they encounter in the virtual airing cupboard. As such, students face a challenge in 'managing the presentation of who they are and who they are perceived to be' (Hult, 2013). Postdigital positionality is a powerful way to point to the problems associated with any decontextualised understanding of student subjectivities and to provide more plural accounts which fill in the gaps that are omitted in McPolicy for the student experience.

A recent $\mathrm{BBC}$ news story covering the decision made by student Zoe Petre from Wales to post her revision notes on Instagram provides one example of postdigital positionality, as enacted by a biomedical science student (BBC, $2020 \mathrm{~g}$ ). Zoe's choice to do this when her exams were not going well was based on her feeling that she needed new techniques to motivate herself. Zoe photographed her handwritten revision notes, uploaded these to her @ZoeStudies account on Instagram and added her own comments on her motivation to do this and what she has learnt on how best to study. The process that Zoe chose to follow illustrates her personal postdigital context, through the combination 
of transferring what she worked on with pen and paper, onto a digital system, adding her thoughts and emotions. Initially followed just by her own friends, her postings have now gained a worldwide audience of followers who were encouraging her to succeed at her course. Zoe describes how she wanted her notes 'to look nice so I want to look at them and learn'. Her notes have become something she wants to revisit. She adds that: 'I also really try and understand them, then condense them so it's easier for revision' and she comments that 'I find Instagramming pushes me and helps me to track my progress, as I always record my highs and lows' (BBC, 2020g). Numerous embodied and external aspects are therefore at play, as each of us live learning experiences and perceive meaning via personal positionality. Our perceptions of identity may be altered too at any number of complex intersections.

\subsection{The Changing Labours of Learning and Teaching}

Earlier in this chapter the issue of a separation between the interconnected labours of learning and teaching was raised in relation to placing students in a 'deficit' model and 'victim culture' (Furedi, 2016). During the pandemic there have been questions of 'scapegoating' too where a blame culture has attributed students as a group who haven't followed the rules or have indulged in 'wilful misbehaviour' (Reicher, 2020). The problem once more of treating students as if they were a homogenous category arises when viewpoints like this flood the virtual airing cupboard. There is scope for such ideas to be conflated too, with standardised views of generations, such as 'Millenials' or 'Generation Z' meeting with backlash from young people who simply prefer not to be called anything (Bromwich, 2018). The issue of cohesive generations, and seeking scapegoats amongst them, has also been addressed by Caitlin Fisher (2019) who argues that a form of gaslighting (or psychological manipulation) takes place around young people now on 'a societal level'. She raises the issue that terms like 'Millenials' seem to be used in relation to how university faculties should 'handle' this generation of students. She cites divisive forms of knowledge that seem to accompany this perspective, including notions that 'Millenials need participation trophies' or Millenials are 'hard to work with' or 'special snowflakes' (Fisher, 2019).

There are other authors who maintain though, that students attending university now are very different from those entering universities a few decades ago. They suggest 'attention should be paid to the characteristics of students, their expectations and needs, as an important criterion for determining the university's role and its contributions at this time' (González-Sanmamed, Sangrà, Souto-Seijo \& Estévez, 2020: 86). Characteristics are though, rather different to a mass categorisation or the assumption of a mass shared 'experience'. They 
argue that at the same time, the role of university teachers also merits reflection across the range of demands that they are now required to meet and the implications this has for their training and professionalisation. In the light of earlier discussion about the educationalisation of so many social issues into universities as well as the overcrowding aspects, it is hard to see how expectations of high levels of quality and personalised attention can be achieved (GonzálezSanmamed, Sangrà, Souto-Seijo \& Estévez, 2020: 86). These authors also argue that young people have grown up in a very different cultural environment to previous generations, which is reflected in their behaviours, relationships and expectations as well as their way of attending, participating and learning at university (González-Sanmamed, Sangrà, Souto-Seijo \& Estévez, 2020: 86). Whilst these are factors that might be attributed to a good number of undergraduates, avoiding generalisations is important. There are also many other diverse learners of different ages and circumstances whose positions will vary too.

\subsection{Inclusivity as Personalised AI or Access and Participation}

In a postdigital landscape there are new configurations also of what a human is, or might be, that will alter our former perceptions of equality, diversity and inclusivity. This is because there are new intersections to consider between AI and perceptions of what is meant by a discourse of 'inclusive education', related teacher functions and pedagogical approaches. Breines and Gallagher (2020) undertook research to identified use cases for bots. They asked, in what educational spaces bots might be situated, and how these would supplement the teacher function, rather than replace it. They advocate a continuous engagement with the community of educators and students in order to shift away from marketised discourses and students as passive recipients of information towards more collaborative development of educational technologies. (Breines \& Gallagher, 2020: 1). Given that universities 'generally rely heavily on third party commercial services for their educational technologies' there has been a problem where 'narratives of solutionism' (Morozov, 2013) have been the dominant discourse. Instead, AI could be a means to support teachers, and augment teaching roles and human intelligence (Cukurova, Kent \& Luckin, 2019: 3033). This then reinforces the types of entanglements that this book is concerned with, where policies for inclusive teaching practices now need to address not only the relations between humans, but also 'the networks of humans and things through which teaching and learning are translated and enacted' (Fenwick, Edwards \& Sawchuk, 2015: 6).

Knox, Wang and Gallagher (2019) examine and compare the discourses that can typically accompany AI technology which is expected: 'to disrupt and enhance educational practice' and, on the other hand, the policy discourse 
that 'appeals for greater inclusion in teaching and learning'. They suggest that in both discourses a future of 'education for all' is envisaged. However, in AI in education (AIEd) 'the idea of an automated, and personalised, one-to-one tutor for every learner' is put forward, whilst the broad mantra of 'inclusive education often appears more concerned with methods of involving marginalised and excluded individuals and organising the communal dimensions of education' (Knox, Wang \& Gallagher, 2019). The distinctions between 'attempts at collective educational work through inclusive pedagogies and the drive for personalised learning through AIEd' are critically discussed:

A quest for personalisation through AIEd is concluded to have 'a problematic grounding in the myth of the one-to-one tutor and questionable associations with simplistic views of 'learner-centred' education. In contrast, inclusive pedagogy is suggested to be more concerned with developing a 'common ground' for educational activity, rather than developing a one-on-one relationship between the teacher and the student. Inclusive education is therefore portrayed as political, involving the promotion of active, collective, and democratic forms of citizen participation. (Knox, Wang \& Gallagher, 2019)

Examining diversity via a postdigital lens holds relevance for all citizens, who now share the commonality of being digitised and datafied, whether they actually opt to go online or not.

\subsection{The Lives of Both Learners and Teachers Are Digitised and Datafied}

In the light of rapid digital and biodigital changes discussed so far, different configurations to the taught disciplines are likely to follow. Furthermore, shared global aspirations around sustainability and the bioeconomy give promise of much interdisciplinary and cross-sector collaboration (Peters, Jandrić \& Hayes, 2021b). Changes to how teachers and students interact would seem to be inevitable too. These developments seem likely to begin to override the increasingly tired McPolicy argument that teachers are simply delivering 'the student experience' and need to be measured to become more efficient in doing so. When both learners and teachers are digitised and datafied across corporate platforms there are related ontological and epistemological considerations (Van Dijck, 2014). Critical debate is needed to redraw educational roles and critical pedagogies when critical reason itself now requires a biodigital interpretation (Peters, Jandrić \& Hayes, 2021a).

There is much scope for research to be undertaken jointly by students and teachers to learn more about their mutually constitutive relationships with 
non-humans and with each other, as blurred, but not separate narratives. At the institutional level too, new values will need to be explored with regard to decisions to supplement teacher functions and to understand the implications relating to visibility and invisibility online, transparency and aspects of hidden curricula of both HE and educational technology itself (Gallagher \& Breines, 2020, Gallagher, Breines \& Blaney, 2020). Teachers and learners alike are now caught up in the 'entire ecosystem of connective media' (Van Dijck, 2014) where the cultural, technological and biological wellbeing of students or teachers cannot be separated from all aspects of their lives, or from the wider community across the virtual airing cupboard. The discourse of McPolicy, that seeks to measure the perceived excellence of teaching practices as somehow separate from other parts of this ecosystem can only produce flawed results. Instead the diverse positionalities of all of those in the ecosystem need to be considered if inequalities that occur at numerous intersections are to be addressed (Equality and Human Rights Commission, 2017: 50). What is missing currently is a consensus, in this context of broader postdigital convergence, of how HE policies now need to converge too. 